Journal of Research in Interprofessional

Practice and

Education

Vol. 2.2

February, 2012

\section{Evaluation of a Simulation-Based Interprofessional Educational Module on Adult Suctioning Using Action Research}

\author{
Cynthia Baker, RN, PhD; Jennifer Medves, RN, PhD; Marian Luctkar- \\ Flude, RN, MScN; Diana Hopkins-Rosseel DEC., BSc (PT), MSc; \\ Cheryl Pulling, RN, MSN; \& Carly Kelly-Turner, BA
}

\begin{abstract}
Background: Interprofessional collaboration in healthcare contributes to patient well-being. The purpose of this action research study was to evaluate an innovative interprofessional simulation educational module for pre-licensure healthcare students on adult suctioning skills.

Methods and Findings: Two suctioning scenarios were developed to provide multiprofessional groups of students the opportunity to collaborate in applying basic suctioning skills within complex patient care situations. One group of nursing students $(N=23)$ and one group of physiotherapy students $(N=23)$ learned suctioning skills uniprofessionally in the usual programs of their respective schools. A third group of students ( $N=45 ; 21$ nursing, 24 physiotherapy) learned suctioning in the new, interprofessional simulation-based curriculum. Qualitative data were collected through direct observation of laboratory sessions, open-ended surveys, and focus groups. A thematic qualitative analysis was conducted, and four major themes emerged: instructors' role expectations, prior student learning, student collaboration, and instructor communication. In addition, quantitative analysis of students' readiness for interprofessional collaboration, confidence, and performance of suctioning skills revealed no significant differences between learners in the interprofessional labs and those in the uniprofessional labs.

Conclusions: Development of the educational module using action research allowed for further development of a pedagogical approach to interprofessional education to increase its effectiveness.
\end{abstract}

Keywords: Interprofessional education; Patient simulation; Adult suctioning

\section{Introduction}

A simulation-based approach to interprofessional education for pre-licensure healthcare students is being implemented within an action research framework. This project involves a partnership among the schools of medicine, nursing, and rehabilitation therapy of a health science faculty, and includes four competencybased modules that have been developed progressively and introduced incrementally. The ultimate goal in developing the larger simulation-based interprofessional education project is to prepare learners for collaborative, patient-centred practice. As the project is guided by an action research methodology, the introduction of each module is being evaluated to generate knowledge that allows modification and further development of the project while it is being created. The purpose of this article is to describe how the introduction of the first module was evaluated and to identify new knowledge about interprofessional education through simulation 
153

Interprofessional Suctioning Simulation

Baker, Medves, Luctkar-Flude, Hopkins-Rosseel Pulling, \& KellyTurner

Journal of Research in Interprofessional Practice and Education

Vol. 2.2

February, 2012 gained from this evaluation. This simulation-based interprofessional module focuses on nasopharyngeal and endotracheal suctioning, clinical competencies that are traditionally taught uniprofessionally to nursing and physiotherapy students within their respective schools.

Policy makers in many countries have been calling for greater interprofessional collaboration to improve health services. There is a growing recognition of the importance of pre-licensure interprofessional education in making this goal become a reality [1,2]. Learning opportunities where small, multi-professional groups of pre-licensure learners interact respond to practice-relevant issues has been identified as a key component of successful interprofessional education initiatives [3]. As high-fidelity patient simulation-based learning involves small groups of students who work together to respond to realistic, clinical situations, the four interprofessional modules in the project incorporate this educational approach.

\section{Theoretical framework}

The theoretical framework underpinning this approach represents a synthesis of conceptual notions borrowed from two sociocultural schools of thought-frameworks for the development of cultural competence, and Durkheim's theory of organic and mechanical solidarity. Cultural competence, the provision of culturally appropriate care to diverse populations, is built on awareness both of one's own culture and of other cultures [4]. Without this awareness, individuals are often unable to perceive cultural differences or understand the behaviours of individuals from other cultural groups. We argue that each healthcare profession has a culture of beliefs, values, knowledge, and skills transmitted through professional training; that interprofessional collaboration requires a type of cultural competence; and that interprofessional education needs to develop this cultural competence among students through learning opportunities that increase cultural awareness of one's own and other professions.

Cohesion and teamwork are central components of effective interprofessional collaboration [5]. Emile Durkheim (1933) introduced the concepts of mechanical and organic solidarity in a classic sociological work on social cohesion. He divided societies into two major types based on the nature of their social cohesion. Mechanical solidarity, the cohesion in societies with little division of labour, is achieved because individuals are doing the same activities and, therefore, share knowledge, skills, and values. In contrast, organic solidarity is the cohesion generated through a division of labour, which generates interdependence and interconnections among the parts [6]. Our approach to interprofessional teaching and learning prepares future health professionals to work in cohesive collaboration through realistic, contextually rich learning opportunities of both types: joint, sideby-side learning of shared competencies and collaborative learning of complementary competencies involving a division of labour within the interprofessional team.

Competencies refer to the sets of knowledge, problem-solving abilities, judgments, interpersonal attitudes, and technical skills relevant to particular occupational situations $[7,8]$. In recent years, there has been an interest in identifying and 
154

Interprofessional Suctioning Simulation

Baker, Medves, Luctkar-Flude, Hopkins-Rosseel Pulling, \& KellyTurner

Journal of Research in Interprofessional Practice and Education

Vol. 2.2

February, 2012 targeting core competencies related specifically to interprofessional collaboration, such as teamwork, effective cross-professional communication, and knowledge and respect of the contributions of other professions [9]. Whereas our theoretical framework identifies professional cultural awareness and interprofessional solidarity as central to interprofessional collaboration, our simulation-based modules are organized around a typology we developed of profession-specific, shared, and complementary clinical competencies. Profession-specific competencies are clinical competencies that are part of the scope of practice of a single health profession and are, therefore, only taught to learners in this profession. In contrast, shared competencies refer to identical or very similar competencies taught to learners in each of the health professions involved in an interprofessional module. Verma, Paterson, and Medves have demonstrated that a surprising number of the core professional competencies identified by medicine, nursing, physical therapy, and occupational therapy in Canadian professional practice standards are, in fact, shared [10]. Finally, a complementary competency is an interconnected set of both shared and profession-specific competencies that form an interactive, collaborative whole in practice situations. Examples of complementary competencies are cardiac resuscitation and maternal delivery of a newborn.

Two modules in the simulation-based curriculum focus on complementary competencies and two target shared competencies. As already indicated, adult suctioning, a shared competency, was the first module to be developed and implemented. Although learning common competencies in parallel does not require the type of interprofessional, interactive teamwork required in the complementary competency modules, we predicted learning shared competencies in multiprofessional learner groups working together with high-fidelity patient simulators would foster greater interprofessional cultural awareness and interprofessional cohesiveness [11]. Thus, two simulation scenarios were developed for students in which the patient simulator requires suctioning. One involves suctioning a ventilated patient via an endotracheal tube, who subsequently develops a cardiac arrhythmia, and the second involves suctioning a patient with an acquired brain injury via a tracheostomy who develops increased intracranial pressure during suctioning. The scenarios provide multiprofessional groups of students the opportunity to collaborate in applying basic suctioning skills learned and practiced together (in the first part of the lab session) to a dynamic and complex patient care situation. The interprofessional suctioning labs were co-taught by a nursing instructor and a physiotherapy instructor.

\section{Anticipated outcomes}

The aims of each module were to raise participants' awareness of the culture of the other participating professions, as well as their own, and to develop a sense of cohesion among the interprofessional learners, while fostering mastery of the specific set of shared or complementary clinical competencies being targeted. Thus, the outcomes anticipated for each module were: 1) increased interprofessional cultural awareness among learners and instructors, 2) increased readiness of learners to 
155

Interprofessional Suctioning Simulation

Baker, Medves, Luctkar-Flude, Hopkins-Rosseel Pulling, \& KellyTurner

Journal of Research in Interprofessional Practice and Education

Vol. 2.2

February, 2012 work collaboratively with other health professionals, and 3) learner integration of the particular clinical competencies being taught in the module.

For the purposes of this project, interprofessional cultural awareness refers to an awareness of the roles and competencies of one's own profession and the profession of the other group or groups participating in the learning module. Readiness to work collaboratively with other health professionals refers to a sense of cohesion or solidarity among the interprofessional learners. And integration of the clinical competencies refers to the learners' ability to perform the shared or complementary competency being taught.

\section{Methodology}

Action research is well suited to situations where an educational innovation is being introduced because individuals involved in the change participate in the investigative process. Evaluations conducted during the implementation of the innovation serve to generate knowledge to enhance it as it is being created. Action research involves an iterative spiral of planning, implementing, evaluating, and modifying the change or innovation while it is being developed [12]. The goal in evaluating the implementation of the interprofessional simulation-based suctioning module was, therefore, to develop new knowledge that would allow us to further develop our pedagogical approach to interprofessional education and increase its effectiveness.

The action research spiral began with a general plan for an interprofessional advisory committee to select four sets of either shared or complementary competencies to be introduced successively over a three year period. In addition, interprofessional faculty working groups were established to create and deliver four modules incorporating high-fidelity simulation. Finally, an evaluation plan was developed that included both a formative process assessment of factors facilitating and impeding the project's success, as well as an evaluation of the anticipated outcomes. The evaluation plan was initiated with the implementation of the suctioning module. Evaluation findings were used by the advisory committee to modify the design framework and the implementation process of successive modules.

Because the suctioning module was introduced midway through the winter term of 2007-2008, 23 nursing students and 23 physiotherapy students who were assigned to the adult suctioning lab in January 2008 learned it uniprofessionally in the usual program of their respective schools. They served as control groups. Fortyfive students were scheduled for this lab in March and April 2008 and learned suctioning in the new interprofessional simulation-based curriculum. All but two students in the physiotherapy control group and two students in the interprofessional group were female. The nursing students were in the third year of a four-year undergraduate program, whereas the physiotherapy students were in the first year of an entry to practice, two-year Master's program. The nursing students had had at least two clinical placements in the acute care sector. In contrast, the physiotherapy students had not had a clinical placement in a hospital setting.

Both uniprofessional and interprofessional lab sessions began with instructors providing a step-by-step explanation of nasopharyngeal, endotracheal, and tra- 
Interprofessional Suctioning Simulation

Baker, Medves, Luctkar-Flude, Hopkins-Rosseel Pulling, \& KellyTurner

Journal of Research in Interprofessional Practice and Education

Vol. 2.2

February, 2012

\section{Journal of Research in Interprofessional Practice and Education}

cheostomy suctioning procedures. This introduction was followed by paired practice time on low-fidelity mannequins, with instructors rotating to answer questions. The uniprofessional lab lasted one hour. In the interprofessional laboratory session, the demonstration and practice session was followed by two simulation scenarios, using high-fidelity patient simulators, in which the suctioning skills were part of a complex patient care situation. The interprofessional lab took place over a two-hour period. Preparation prior to the session included online readings, a PowerPoint presentation, and a demonstration videotape that were all posted on the interprofessional simulation project's website.

Two instructors taught the interprofessional lab. One, who was enrolled in a $\mathrm{PhD}$ program in rehabilitation therapy, had been teaching suctioning in the physiotherapy lab for two years. The second, with a Master's degree in nursing, had been a clinical instructor to nursing students for over three years and had also been a lab instructor in the nursing program. They received an orientation to the learning module.

\section{Data collection}

Mixed methods were used to assess the module implementation process and the achievement of the anticipated, immediate outcomes. The implementation process, interprofessional cultural awareness, and readiness for interprofessional collaboration were evaluated qualitatively through direct observation of one uniprofessional suctioning lab session for physiotherapy students, one uniprofessional lab session for nursing students, and four interprofessional simulation labs. Three focus group sessions were also conducted, one among nursing students in the usual professionspecific labs, one among physiotherapy students in the usual profession-specific labs, and one among students in the interprofessional suctioning labs. In addition, readiness for interprofessional collaboration was assessed using a communication and teamwork scale. Finally, students' integration of the suctioning competencies was evaluated following the labs using a performance checklist and a Likert-type scale measuring their self-reported confidence in performing the procedure. Each data collection method is described in greater detail below.

\section{Observations of the labs}

Two research associates attended and conducted unstructured observations of the uniprofessional nursing and physiotherapy labs and the four interprofessional labs. They focused their observations on the following types of interactions: a) between instructors, b) between instructors and students, and c) among students. They took detailed notes and, for each lab session, amalgamated their observations into one record immediately following the session. While carrying out their observations they spent some of the time in the lab behind the students, where they would not interfere with the learning activities, and they spent some of the time observing from behind a two-way mirror.

Focus groups

Each focus group was conducted by two research associates, and one research asso- 


\section{JRIPE}

157

Interprofessional Suctioning

Simulation

Baker, Medves, Luctkar-Flude, Hopkins-Rosseel Pulling, \& KellyTurner
Journal of Research in Interprofessional Practice and Education

Vol. 2.2

February, 2012

\section{Journal of Research in Interprofessional Practice and Education}

ciate transcribed them. A protocol of ten questions about the structure of the learning module, the teaching strategies, and the learning environment was used to guide the focus groups (see Table 1).

\section{Table 1}

\section{Focus group questions}

Structure of the Lab

i) How effective would you say was the manner in which the suctioning lab was taught?

ii) Would you take anything out of the lab or add anything?

Didactic demo?

Torso practice in pairs of groups of 3 ?

Simulation scenarios?

Confidence

iii) How confident did you feel in your ability to suction patients leaving the lab?

Teaching strategies

iv) How did you feel about the dynamic between the instructors?

Flow between the instructors?

Instructor communication?

v) Did instructors go through all steps thoroughly enough?

Challenges

vi) Did you experience any challenges within the lab?

With instructors?

With the practice portion?

Multiprofessional Learning Groups

vii) Did you feel that learning with students in another discipline was effective?

viii) Did you learn more about that discipline's roles and responsibilities?

Summary

ix) Would you suggest anything to make this lab more beneficial to learners?

\section{Questionnaire}

The questionnaire administered to learners following the labs included the Communication and Teamwork Scale developed by Pollard, Miers, and Gilchrest [13]. It consists of 9 items on a 6-point Likert-type scale. An earlier study of its reliability found a .78 correlation coefficient for scores on a test-retest administration, and a Cronbach's alpha coefficient of .76 [13]. The questionnaire also included four open-ended questions regarding students' interprofessional awareness and attitudes about interprofessional learning, and a six-item, six-point scale assessing their selfreported confidence in performing the suctioning techniques they had learned. 
Interprofessional Suctioning Simulation

Baker, Medves, Luctkar-Flude, Hopkins-Rosseel Pulling, \& KellyTurner
Journal of Research in Interprofessional Practice and Education

Vol. 2.2

February, 2012
Journal of Research in Interprofessional Practice and Education

\section{Performance checklist}

For the performance assessment, the student was asked to go through the steps of either endotracheal or nasopharyngeal suctioning while an evaluator followed along with a checklist, marking either met, or needs improvement. The evaluation lasted approximately $8 \mathrm{~min}-$ utes and was conducted after the lab session. The procedural checklist was based on interprofessional practice guidelines that were developed for the project using a rigorous, systematic, evidence-based knowledge synthesis method. All of the skills in the checklist were treated as equally important. Evaluators trained by the project coordinator observed and assessed the performance of consenting students.

\section{Respondents}

Responding to the questionnaire, participating in the checklist evaluation, and participating in the focus group were all voluntary. Students were given an explanation of the purpose of the study and the nature of their proposed participation. All participants signed consent forms. Nineteen of the 23 nursing students $(83 \%)$ in the uniprofessional control labs responded to the questionnaire, and $11(45 \%)$ returned for the checklist assessment (turnout was low because of exam-related pressures on their time); 19 of the 23 physiotherapy students (83\%) in the uniprofessional control labs responded to both of these; and 32 of the 45 (71\%) students in the interprofessional labs responded to the questionnaire and checklist. Out of 91 students, $17(19 \%)$ volunteered to participate in a focus group. Participant and survey respondent numbers are summarized in Tables 2 and 3.

Table 2:

\section{Nursing and physiotherapy students in suctioning labs 2007-2008}

\begin{tabular}{|l|c|c|}
\hline & $\begin{array}{c}\text { Uniprofessional suctioning lab } \\
\text { (controls) }\end{array}$ & $\begin{array}{c}\text { Interprofessional } \\
\text { suctioning lab (experimental) }\end{array}$ \\
\hline Nursing students & 23 & 21 \\
\hline Physiotherapy students & 23 & 24 \\
\hline Total & 46 & 45 \\
\hline
\end{tabular}

\section{Ethics}

This study received approval from the Queen's University Health Sciences Research Ethics Board. Informed consent was obtained from all study participants.

\section{Data analysis}

A qualitative thematic analysis was carried out using transcripts of the detailed observations, focus groups, and open-ended survey questions. Data collected using the questionnaire scales and the checklists were entered into SPSS. Independent $t$-tests for items on the Likert-type scales were conducted, comparing students in the interprofessional group with students in the control labs. Chi-square analyses were conducted, comparing performance, as measured by the checklist scores, of students in the interprofessional groups with students in the control groups. 
159

Interprofessional Suctioning Simulation

Baker, Medves, Luctkar-Flude, Hopkins-Rosseel Pulling, \& KellyTurner

Journal of Research in Interprofessional Practice and Education

Vol. 2.2

February, 2012

\section{Findings}

All labs began with a didactic instructional session and a demonstration of the suctioning procedures, followed by students practicing in groups of two or three using low-fidelity mannequins. In the interprofessional labs, the two simulation scenarios followed, wherein groups of nursing and physiotherapy students provided care to high-fidelity patient simulators manifesting complex medical conditions. One scenario required tracheostomy suctioning, the other, endotracheal tube suctioning.

\section{Qualitative analysis}

A thematic qualitative analysis was conducted on the recorded laboratory session observations, the responses to the four open-ended survey questions, and the focus group records. These data were treated as text and coded, the codes were categorized, and, finally, themes were identified. Four major themes emerged from this process: instructors' role expectations, prior student learning, student collaboration, and instructor communication.

\section{Instructors' role expectations}

As noted, the team systematically developed evidence-based interprofessional practice guidelines prior to the project implementation as a way of bridging professional differences in the content of the module. However, observations of the uniprofessional labs revealed some differences in the teaching method that the interprofessional team was unaware of when they planned the module. In the physiotherapy lab, a teaching assistant read each step in the suctioning procedure while the instructor demonstrated each step as it was read. In the nursing lab, the instructor first outlined the procedure in a more discursive form and then demonstrated it herself.

The observers recorded that there was some confusion among instructors about their respective roles in conducting the lab, noting that they used a different process to present the suctioning procedures in each lab. Except for the third lab, they appeared to feel some awkwardness about how they should teach the lab. In the first interprofessional lab, the physiotherapy instructor took the lead and demonstrated the procedure in the same way it was done in the uniprofessional physiotherapy labs. The nursing instructor began to read some of the steps, but the ventilator started to malfunction, and she stopped to manage the machine during the remainder of the demonstration. In the second interprofessional lab, the physiotherapy instructor demonstrated the procedure, and, rather than read each step, the nursing instructor contributed the occasional comment or explanation of the step being demonstrated. In the third lab, the physiotherapy instructor read the steps of the procedure, and the nursing instructor demonstrated it. They positioned themselves on either side of the bed facing each other and presented the procedure as a team. In the fourth lab, the physiotherapy instructor took the lead and demonstrated the procedure, and the nursing instructor assisted her occasionally.

Prior student learning

The physiotherapy and nursing students came to the lab sessions with different 
160

Interprofessional Suctioning

Simulation

Baker, Medves, Luctkar-Flude, Hopkins-Rosseel Pulling, \& KellyTurner

Journal of Research in Interprofessional Practice and Education

Vol. 2.2

February, 2012 prior learning experiences and at different points in their respective programs. The nursing students had been in clinical placements in the acute care setting and had also had previous labs using high-fidelity simulators. The physiotherapy students had not yet had a clinical placement nor used the simulators. This influenced their understanding of what was being taught and their facility in carrying out procedures. For instance, the observers noted that the term sterile field was frequently used, and although the nursing students appeared to understand the concept, the physiotherapy students did not. Explanations of sterile field, however, were not part of the teaching, as the content of the module was focused on the evidence-based practice guidelines for suctioning. Similarly, because of their prior clinical and lab experiences, the nursing students were more familiar and comfortable with the monitors and other hospital equipment used in the simulation scenarios than the physiotherapy students. Instructors responded to this extemporaneously. Halfway through the first lab, the physiotherapy instructor halted the lab in response to a student's question and explained all of the equipment. In the second and fourth lab, however, no questions were asked and no instruction about the equipment was given. In the third lab, the nursing instructor explained equipment when demonstrating procedures.

Physiotherapy students' responses to the open-ended survey question about experience working with another profession supported the recorded observations regarding differences in prior learning. For instance, one student commented that they were "less prepared than it seems the nursing students were, in terms of names of machines." Similarly, another commented, "nursing students were comfortable in working in a hospital setting and were able to explain procedures/machines." The focus group data also supported this observation. For instance, one physiotherapy student said, "I found that there were some things I knew nothing about, stuff like turning on the oxygen and stuff which was just sort of 'done."'

\section{Student collaboration}

At the beginning of each lab, and during the demonstration, nursing students stood together on one side of the room and the physiotherapy students stood in another group on the other side of the room. In the practice session that followed, they were paired with a student from the other profession, and in the simulation scenarios, they were in interprofessional groups. The observers noted that students collaborated with each other well in the practice sessions, discussed the procedure with each other, and asked each other for help and support. As the session progressed, many would also ask questions about the other's profession and the role suctioning played in their scope of practice.

Responses to the open-ended survey question and the focus group data indicated that both the nursing students and the physiotherapy students felt the interprofessional collaboration was positive and valued it. For instance, one student commented, "we each offer different backgrounds of information and thus collaborated to help each other." Another stated that "we get to share each other's experiences and strengths." 


\section{JRIPE}

161

Interprofessional Suctioning

Simulation

Baker, Medves, Luctkar-Flude, Hopkins-Rosseel Pulling, \& KellyTurner

\section{Instructor communication and collaboration}

The interprofessional labs involved teaching a shared competency together rather than teaching profession-specific competencies involving teamwork. Both instructors were, in fact, capable of instructing the lab without the other. In other words, there was nothing in the module itself to create a link between them or foster teamwork. The observers recorded that the instructors communicated with each other very little and responded separately to situations that arose rather than in collaboration. Students in the focus groups also noted this. One explained, "they just sort of seemed like they were on different pages."

\section{Quantitative analysis}

The only significant difference between students in the interprofessional and the uniprofessional labs on the Communication and Teamwork Scale assessing readi-

Table 3:

\section{Number of Respondents}

\begin{tabular}{|l|c|c|c|}
\hline & $\begin{array}{c}\text { Nursing Control } \\
\text { Labs }\end{array}$ & $\begin{array}{c}\text { Physiotherapy } \\
\text { Control Labs }\end{array}$ & $\begin{array}{c}\text { Interprofessional } \\
\text { Labs }\end{array}$ \\
\hline Questionnaire & $19 / 23$ & $19 / 23$ & $32 / 45$ \\
\hline Assessment checklist & $11 / 23$ & $19 / 23$ & $34 / 45$ \\
\hline Focus group & $3 / 23$ & $7 / 23$ & $7 / 45$ \\
\hline
\end{tabular}

Table 4:

\section{Interprofessional learners compared with control group in communication and teamwork}

\begin{tabular}{|l|c|c|}
\hline Item & $\begin{array}{c}\text { T-test } \\
\text { (equal variance } \\
\text { not assumed) }\end{array}$ & $\begin{array}{c}\text { Sig } \\
\text { (2 tailed) }\end{array}$ \\
\hline $\begin{array}{l}\text { I feel comfortable justifying recommendations and/or advice } \\
\text { face to face with more senior people. }\end{array}$ & 1.540 & 0.131 \\
\hline $\begin{array}{l}\text { I feel comfortable explaining an issue to people who are } \\
\text { unfamiliar with the topic. }\end{array}$ & 1.589 & 0.118 \\
\hline $\begin{array}{l}\text { I have difficulty in adapting my communication style to } \\
\text { particular situations and audiences. }\end{array}$ & 0.505 & 0.616 \\
\hline $\begin{array}{l}\text { I prefer to stay quiet when other people in a group express } \\
\text { opinions that I don't agree with. }\end{array}$ & 1.953 & 0.056 \\
\hline \begin{tabular}{l} 
I feel comfortable working in a group. \\
\hline I feel uncomfortable putting forward my personal opinions in a group.
\end{tabular} & 1.032 & 0.671 \\
\hline \begin{tabular}{l} 
I feel uncomfortable taking the lead in a group. \\
\hline I am able to become quickly involved in new teams and groups.
\end{tabular} & 0.925 & 0.307 \\
\hline $\begin{array}{l}\text { I am comfortable expressing my own opinions in a group even } \\
\text { when I know that other people don't agree with them. }\end{array}$ & 1.569 & 0.359 \\
\hline
\end{tabular}

Journal of Research in Interprofessional Practice and Education

Vol. 2.2

February, 2012 
JRIPE

162

Interprofessional Suctioning Simulation

Baker, Medves, Luctkar-Flude, Hopkins-Rosseel Pulling, \& KellyTurner

ness for interprofessional teamwork was an independent item stating, "I am able to become quickly involved in new teams and groups" $(p=.001)$. There was, therefore, little quantitative evidence that the simulation-based interprofessional labs increased students' readiness for interprofessional collaborative practice (Table 4).

The results of the performance checklist items indicated that most of the 20 steps were carried out correctly by at least $75 \%$ of the students following the interprofessional lab. Less than $75 \%$ performed four skills in nasopharyngeal suctioning appropriately: 1) positioning the patient (25\%), 2) setting the vacuum pressure (66\%), 3) sliding the catheter out (44\%), and 4) documenting secretions (25\%). Either a lesser or equal percentage of the uniprofessional control group performed each of these

Table 5

\section{Number of students meeting each performance checklist skill in nasopharyngeal suctioning by type of lab}

\begin{tabular}{|l|c|c|c|}
\hline Checklist Item & Uniprofessional labs & Interprofessional labs & ${ }^{*}$ P value \\
\hline Assess for suctioning & $9 / 16(56 \%)$ & $15 / 16(94 \%)$ & .014 \\
\hline Explain procedure & $7 / 15(47 \%)$ & $12 / 16(75 \%)$ & .106 \\
\hline Position patient & $1 / 14(7 \%)$ & $2 / 8(25 \%)$ & .240 \\
\hline Apply face shield & $15 / 16(94 \%)$ & $14 / 16(88 \%)$ & .544 \\
\hline Turn on wall suction & $11 / 12(92 \%)$ & $14 / 16(88 \%)$ & .869 \\
\hline Set vacuum pressure & $7 / 15(47 \%)$ & $4 / 6(66 \%)$ & .407 \\
\hline Pour saline & $11 / 15(73 \%)$ & $13 / 16(81 \%)$ & .598 \\
\hline Connect catheter & $15 / 15(100 \%)$ & $15 / 15(100 \%)$ & \\
\hline Apply sterile gloves & $13 / 16(81 \%)$ & $16 / 16(100 \%)$ & .069 \\
\hline Slide catheter out & $5 / 16(31 \%)$ & $7 / 16((44 \%)$ & .465 \\
\hline Keeping sterile & $14 / 16(88 \%)$ & $14 / 16(88 \%)$ & \\
\hline Measure insertion & $15 / 16(94 \%)$ & $15 / 16(94 \%)$ & \\
\hline Suction up saline & $13 / 16(81 \%)$ & $11 / 15(73 \%)$ & .685 \\
\hline Insert catheter & $15 / 16((94 \%)$ & $15 / 16(94 \%)$ & \\
\hline Apply suction & $14 / 16(88 \%)$ & $12 / 16(75 \%)$ & .365 \\
\hline Rinse catheter & $13 / 16(81 \%)$ & $11 / 15(73 \%)$ & \\
\hline Determine completed & $13 / 14(93 \%)$ & $7 / 8(88 \%)$ & .674 \\
\hline Number of passes & $14 / 16(88 \%)$ & $7 / 8(88 \%)$ & .484 \\
\hline Turn off-reassess & $11 / 16(68 \%)$ & $13 / 16(81 \%)$ & \\
\hline Remove gloves & $16 / 16(100 \%)$ & $14 / 16(88 \%)$ & \\
\hline Document secretions & $4 / 16(25 \%)$ & $4 / 16(25 \%)$ & \\
\hline
\end{tabular}

Notes: Competency: Set of knowledge, problem solving abilities, judgments, interpersonal attitudes, and technical skills relevant to particular occupational situations; ${ }^{*}$ Chi square

Journal of Research in Interprofessional Practice and Education

Vol. 2.2

February, 2012 
163

Interprofessional Suctioning

Simulation

Baker, Medves, Luctkar-Flude, Hopkins-Rosseel Pulling, \& KellyTurner
Journal of Research in Interprofessional Practice and Education

Vol. 2.2

February, 2012
Table 6

\section{Number of students meeting each checklist skill in endotracheal suctioning by type of lab}

\begin{tabular}{|l|c|c|c|}
\hline Checklist Item & Uniprofessional & Interprofessional & ${ }^{*}$ P value \\
\hline Assess for suctioning & $8 / 16(50 \%$ & $18 / 18(100 \%)$ & .001 \\
\hline Explain procedure & $4 / 15(27 \%)$ & $15 / 18(83 \%)$ & .001 \\
\hline Position patient & $1 / 13(8 \%)$ & $7 / 15(47 \%)$ & .023 \\
\hline Apply face shield & $15 / 15(100 \%)$ & $15 / 18(83 \%)$ & .097 \\
\hline Turn on wall suction & $15 / 15(100 \%)$ & $18 / 18(100 \%)$ & \\
\hline Set vacuum pressure & $10 / 15(67 \%)$ & $10 / 11(91 \%)$ & .147 \\
\hline Pour saline & $15 / 15(100 \%)$ & $15 / 16(94 \%)$ & .325 \\
\hline Connect catheter & $15 / 15(100 \%)$ & $18 / 18(100 \%)$ & .233 \\
\hline Apply sterile gloves & $13 / 16(81 \%)$ & $17 / 18(94 \%)$ & .582 \\
\hline Slide catheter out & $15 / 16(94 \%)$ & $15 / 18(83 \%)$ & .339 \\
\hline Keeping sterile & $16 / 16(100 \%)$ & $17 / 17(100 \%)$ & .582 \\
\hline Suction up saline & $15 / 16(94 \%)$ & $15 / 17(88 \%)$ & .339 \\
\hline Insert catheter & $16 / 16(100 \%)$ & $17 / 18(94 \%)$ & .658 \\
\hline Apply suction & $14 / 15(93 \%)$ & $16 / 18(89 \%)$ & .461 \\
\hline Rinse catheter & $13 / 15(87 \%)$ & $13 / 17(76 \%)$ & .362 \\
\hline Determine completed & $7 / 7(100 \%)$ & $8 / 989 \%)$ & .308 \\
\hline Number of passes & $13 / 13(100 \%)$ & $12 / 13(92 \%)$ & .922 \\
\hline Turn off-reassess & $12 / 16(75 \%)$ & $13 / 17(76 \%)$ & $17 / 18(94 \%)$ \\
\hline Remove gloves & $16 / 16(100 \%)$ & $7 / 18(39 \%)$ & .240 \\
\hline Document secretions & $3 / 15(2 \%)$ & & \\
\hline
\end{tabular}

Notes: Competency: Set of knowledge, problem solving abilities, judgments, interpersonal attitudes, and technical skills relevant to particular occupational situations; ${ }^{*}$ Chi square

skills correctly $(7 \%, 47 \%, 31 \%$, and $25 \%$, respectively). Two steps in the endotracheal suctioning were not mastered by the majority of students in the interprofessional group: 1) positioning the patient (47\%) and 2) documenting secretions (39\%). Within the uniprofessional group, only $8 \%$ positioned the patient appropriately and $27 \%$ documented secretions. However, students in the interprofessional lab only performed significantly better than those in the uniprofessional labs on three skills: patient assessment for both nasopharyngeal suctioning $(p=.014)$ and endotracheal suctioning $(p=.01)$, and on explaining the endotracheal suctioning procedure $(p=.01)$. Results of the performance checklists for nasopharyngeal suctioning are summarized in Table 5 and results for endotracheal suctioning in Table 6. 
Interprofessional Suctioning Simulation

Baker, Medves, Luctkar-Flude, Hopkins-Rosseel Pulling, \& KellyTurner
Journal of Research in Interprofessional Practice and Education

Vol. 2.2

February, 2012
There were no significant differences between students in the uniprofessional and the interprofessional labs in their perceptions of their confidence in performing six suctioning skills, except for hyperoxygenating patients $(p=.03)$ (Table 7). The interprofessional learners reported greater confidence performing this skill.

Table 7

\section{Interprofessional group compared with control group in confidence in performing adult suctioning}

\begin{tabular}{|l|c|c|}
\hline Item & $\begin{array}{c}t \text {-test } \\
\text { (equal variance not assumed) }\end{array}$ & $\begin{array}{c}\text { Sig } \\
(2 \text { tailed) }\end{array}$ \\
\hline Confident selecting catheter size & 0.544 & 0.589 \\
\hline Confident hyperoxygenating patients & 3.10 & 0.03 \\
\hline Confident assessing for indications of suctioning & 0.779 & 0.439 \\
\hline Confident performing open suctioning & 0.935 & 0.357 \\
\hline Confident performing endotracheal suctioning & 0.288 & 0.775 \\
\hline Confident performing nasal and oral suctioning & 1.118 & 0.269 \\
\hline
\end{tabular}

\section{Discussion}

As indicated, we anticipated that the interprofessional simulation module on adult suctioning would build interprofessional awareness among students and instructors, and increase students' readiness for interprofessional collaboration. We also expected that students would master the shared suctioning competencies as a result of participating in the high-fidelity-simulation-based interprofessional lab. The qualitative data suggest that the joint learning of a shared competency using highfidelity simulation did enhance the students' cultural awareness of the other profession as well as their own, and that it generated interprofessional cohesion among them. Moreover, these data showed that students were very positive about both the use of high fidelity simulation and the interprofessional component of the suctioning lab sessions. There was little quantitative evidence, however, that our approach increased students' readiness for interprofessional collaboration, based on the measure we used. In addition, the qualitative data indicated that the module, as implemented, did not increase the interprofessional awareness of the instructors.

The negative results of the Communication and Teamwork Scale may have been because the focus of the lab was a shared competency rather than a complementary one where interprofessional interdependence is accentuated. It is important to point out, however, that although the module concerned parallel learning of suctioning, the high-fidelity scenarios included interprofessional collaboration in problem solving to apply this shared competency appropriately in a dynamic clinical situation. The qualitative process evaluation findings provide important information on the implementation itself that need to be taken into account.

The modules were developed jointly by two nursing faculty and a physiotherapy faculty member, who began their planning with a rigorous, evidence-based approach 
165

Interprofessional Suctioning Simulation

Baker, Medves, Luctkar-Flude, Hopkins-Rosseel Pulling, \& KellyTurner

Journal of Research in Interprofessional Practice and Education

Vol. 2.2

February, 2012 to reconcile any differences in how the suctioning procedures were being performed in the two lab courses of each discipline. Despite the role of cultural competence in our theoretical framework, the differences in how instructors in the two schools taught the procedures went unrecognized. It should also be noted that the nursing and physiotherapy educators who collaborated to design and develop the module were not the instructors who taught the modules interprofessionally. Increasingly, educator preparation for interprofessional education is being recommended [14]. Cultural differences that may exist between professions in how they teach is something we need to think about with interprofessional education. The content of such interprofessional training programs for instructors tends to focus on the development of general interprofessional attitudes and skills. Although such programs are undoubtedly helpful, our findings indicate a more content-specific preparation would be beneficial for simulation-based teaching of a shared competency. More specifically, the findings illustrated the need for a cultural assessment of potential differences in teaching procedures and approaches when the module is being planned, and for the development of clear guidelines regarding the interprofessional instruction of labs based on this cultural assessment.

As far as the students' integration of the competency is concerned, the performance checklist assessment indicated that participating in the simulation-based interprofessional lab resulted in the appropriate performance of 16 of the 20 skills in nasopharyngeal suctioning by most students, and 18 of the 20 in endotracheal suctioning. These data suggest that, overall, the interprofessional simulation-based labs were effective in teaching students to perform the competencies, but they also flagged areas that needed greater instructor attention in future delivery of the modules. The limited significant differences on the performance checklist between students in the uniprofessional and the interprofessional simulation surprised us. Besides the teaching issues related to instructor collaboration, it is important to note that most of the skills evaluated were procedural steps in the process. We may not have been evaluating the clinical reasoning/critical thinking component, which is the actual crux of the contextual high-fidelity simulation approach to learning. The skills performed significantly better by students in the interprofessional lab-assessment and explanation of the procedure-were the most dynamic and contextually influenced ones in the checklist and the most reflective of clinical reasoning. Because of organizational barriers, we were unable to include a pre-test of students' performance, a limitation that needs to be recognized in interpreting the three positive findings.

The qualitative process analysis underscores the need to determine before the interprofessional lab potential differences in students' prior learning that may interfere with their performance in the lab. It also indicates that taking steps before the lab to create an even playing field for students from different disciplines might enhance their learning of the clinical competency being taught.

We expected that students in the interprofessional lab would not only perform the competency better than those in the uniprofessional lab but that this would be reflected in a greater confidence in their ability to do so. There was, however, little difference between the two groups. A possible explanation for the negative finding 
Interprofessional Suctioning Simulation

Baker, Medves, Luctkar-Flude, Hopkins-Rosseel Pulling, \& KellyTurner

Journal of Research in Interprofessional Practice and Education

Vol. 2.2

February, 2012

\section{Journal of Research in Interprofessional Practice and Education}

is that students in the interprofessional lab were appraising their ability to mobilize the components of the competency, envisioning a more complex, dynamic, and less predictable context than those assigned to the low-fidelity simulation lab.

In describing twenty years of experience in developing and modifying the Linkoping interprofessional model in Sweden, Wilhelmsson and colleagues (2009) emphasize the importance of constantly evaluating, revising, and discussing the interprofessional model [3]. A number of changes were proposed to the suctioning module as a result of the evaluation. These include an orientation to the physical layout of the simulation lab, the simulators, and the equipment for students who have not had previous experience in the lab through a site visit and an interactive video. Instructor guidelines have been developed for co-instructing the lab, and an interprofessional preparation workshop is provided.

Limitations of the evaluation include a small sample size and no randomization. In addition, the attitudes, confidence, and skills of the students were not surveyed prior to their participation in the educational modules because of organizational barriers. It is, therefore, unclear to what extent their collaboration, confidence, and performance were attributable to prior learning.

\section{Conclusion}

The purpose of action research is to generate new knowledge about the what and the how of a change or innovation to improve it as it is being implemented. In conclusion, the evaluation indicated that the students in both nursing and physiotherapy were enthusiastic about learning a shared competency together through simulation and found the experience valuable. The following general principles related to interprofessional education through simulation were taken from this evaluation to enhance the development and implementation of subsequent modules: Cultural differences in teaching approaches between disciplines need to be identified and taken into account when designing interprofessional educational modules of competencies shared across disciplines. Differences in prior student learning that are relevant to the content of an educational module must be identified and addressed through preparatory instruction and during the actual teaching of the module. And finally, guidelines for interprofessional co-teaching of a shared competency module should be developed and evaluated through further research.

\section{Acknowledgements}

We would like to thank all the study participants and research assistants who contributed to this work, and thanks to Robert Stevenson, BSc, PEng, for his technical expertise. The authors would also like to thank the Interprofessional Health Education Innovation Fund for their financial support.

\section{References}

1. Barr, H., \& Ross, F. (2006). Mainstreaming interprofessional education in the United Kingdom: A position paper. Journal of Interprofessional Care, 20(2), 96-104. 


\section{JRIPE}

167

Interprofessional Suctioning Simulation

Baker, Medves, Luctkar-Flude, Hopkins-Rosseel Pulling, \& KellyTurner

\section{Journal of Research in Interprofessional Practice and Education}

2. Hollenberg, E., Reeves, S., Beduz, M.A., Jeffs, L., Kwan, D., Lee, J. Lowe, M., Merkley, J., Sinclair, L., Tassone, M., \& Oandasan, I. (2009). "Mainstreaming” interprofessional education within hospital settings: Findings from a multiple case study. Journal of Research in Interprofessional Practice and Education, 1(1), 10-23.

3. Wilhelmsson, M., Pelling, S., Ludvigsson, J., Hammar, M., Dahlgren, L-O., \& Faresjö, T. (2009). Twenty years experiences of interprofessional education in Linkoping-ground-breaking and sustainable. Journal of Interprofessional Care, 23(2), 121-133.

4. Srivastava, R. (2007). The health care professional's guide to cultural competence. Toronto, ON: Mosby.

5. Barr H. (2005). Interprofessional education: Today, yesterday and tomorrow: A review, revised edition. London: Higher Education Academy, Health Sciences and Practice Network.

6. Durkheim, E. (1964). The division of labour in society. Toronto, ON: Collier-Macmillan.

7. Defloor, T., Van Hecke, A., Verhaeghe, S., Gobert, M., Darras, E., \& Grypdonck, M. (2006). The clinical nursing competencies and their complexity in Belgium general hospitals. Journal of Advanced Nursing, 56(6), 669-678.

8. Tardif, J. (2006). L'evaluation des competences : Documenter le parcours de developpement. Montreal, QC : Cheneliere Education.

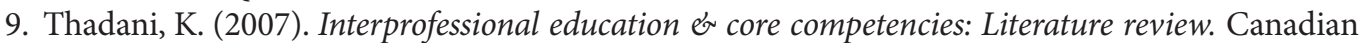
Interprofessional Health Collaborative. URL:'www.cihc.cai'[April 1, 2010].

10. Verma, S., Paterson, M., \& Medves, J. (2006). Core competencies for health care professionals: What medicine, nursing, occupational therapy, and physiotherapy share. Journal of Allied Health, 35(2), 109-115.

11. Baker, C., Pulling, C., McGraw, R., Dagnone, J.D., Hopkins-Rosseel, D., \& Mendes, J. (2008). Simulation in interprofessional education for patient-centered collaborative care. Journal of Advanced Nursing, 64(4), 372-379.

12. Kemmis, S., \& McTaggert, R. (1990). The action research planner. Geelong, VIC: Deakin University Press.

13. Pollard, K.C., Miers, M.E., \& Gilchrest, M. (2004). Collaborative learning for collaborative working? Initial findings from a longitudinal study of health and social care students. Health and Social Care in the Community, 12(4), 346-358.

14. Kwan, D., Barker, K., Richardson, D., Wagner, S.J., \& Austin, Z. (2009). Effectiveness of a faculty development program in fostering interprofessional education competencies. Journal of Research in Interprofessional Practice and Education, 1(1), 24-41.
Journal of Research in Interprofessional Practice and Education

Vol. 2.2

February, 2012 